\title{
Corrupción: la mayor Epidemia que sufre Colombia
}

\author{
Corrupção- a maior Epidemia que sofre a Colômbia
}

\section{Corruption the biggest Epidemic that Colombia SUFFERS}

\author{
Gressy Kareny Rojas Cardona* \\ David Mendieta $^{* *}$
}

\begin{abstract}
1 Introducción. 2 Enfoque histórico y doctrinal de la corrupción. 3 La corrupción en Colombia, una epidemia a la que no se le ha encontrado vacuna. 4 Impacto de la corrupción en tiempos de COVID-19 en Colombia. 5 Consideraciones finales. Referencias.
\end{abstract}

\section{RESUMEN}

Objetivo: Colombia es un país rico en recursos naturales, su producto interno bruto (PIB) se triplicó en los últimos 30 años -según datos de la CEPAL- pero, al mismo tiempo, según el índice Gini del Banco Mundial, es uno de los países más desiguales del mundo. El objetivo principal de este artículo es mostrar el vínculo existente entre corrupción y desigualdad en Colombia y cómo el flagelo producto de esta relación se ha materializado en la actual época de pandemia.

Metodología: Esta investigación es producto de un análisis bibliográfico que sigue el método descriptivo-analítico. El documento está compuesto por tres partes; la primera es una mirada general de la problemática para llegar a su origen, luego se presentan algunas cifras que permiten ilustrar su evolución en el país y, finalmente, se concluirá con algunos ejemplos de corrupción en Colombia, enmarcados en el desarrollo de la pandemia ocasionada por el SARS COVID 19.

* Abogada, Máster en Derecho, Doctoranda, Universidad de Medellín, Colômbia. Correo electrónico <rojascardona.gressykareny@gmail.com>. https://orcid.org/0000-0003-3860-6772

** Doctor en Derecho Constitucional. Director del Doctorado en Derecho de la Universidad de Medellín, miembro del Grupo de Investigaciones Jurídicas de la Facultad de Derecho de la Universidad de Medellín. Medellín- Colombia. E-mail: <dmendieta@udem.edu.co>. https://orcid.org/0000-0002-6944-6815 
Resultados: Se pudo demostrar que la corrupción es la mayor epidemia que sufre Colombia, incluso por encima del conflicto armado o la crisis ocasionada por el virus del COVID - 19.

Contribuciones: En Colombia la corrupción se ha convertido en una epidemia que desangra los recursos públicos y que resulta más onerosa que la financiación de la guerra. La mayor emergencia sanitaria de la historia, ocasionada por el virus del COVID-19, ha requerido la intervención inmediata de las entidades del Estado, permitiendo la contratación directa, pero esto a su vez ha puesto en peligro billones de pesos invertidos, demostrando que en un país como Colombia ni siquiera una crisis sanitaria detiene a los corruptos, al contrario, los estimula.

Palabras clave: Desigualdad. Pobreza. Riqueza. Conflicto armado. COVID19. Corrupción. Epidemia. Colombia.

\section{ABSTRACT}

Objective: Colombia is a country rich in natural resources, its gross domestic product (GDP) tripled in the last 30 years, according to ECLAC data, but at the same time, according to the Gini index of the World Bank, it is one of the countries most unequal in the world. The main objective of this article is to show the relationship between corruption and inequality in Colombia and how this scourge has become evident at the time of the global pandemic.

Methodology: This study is a bibliographic review that follows the descriptive-analytical method. The document is made up of three parts; The first is a general view of the problem to get to its origin, then some figures are presented that give an idea of the evolution in the country to conclude with some examples of corruption that occur at the time of COVID-19 in Colombia.

Results: It was shown that corruption is the biggest epidemic that Colombia suffers, even above the armed conflict or the crisis caused by the COVID -19 virus.

Contributions: In Colombia, corruption has become an epidemic that drains public resources and is more costly for the country than war. The greatest health emergency in history, caused by the COVID-19 virus, has required the immediate intervention of State entities, allowing direct contracting, but this in turn has endangered the billions of pesos invested, showing that In a country like Colombia, crises do not stop the corrupt, but rather stimulate them.

Keywords: Inequality. Poverty. Wealth. Armed conflicto. COVID19. Corruption. Epidemic. Colombia. 


\section{INTRODUCCIÓN}

La riqueza natural de Colombia es reconocida internacionalmente y se manifiesta en diferentes aspectos como diversidad de especies de fauna y flora (LARA; TOSI; ALTIMIRAS, 2020). Adicionalmente, tiene como bien transable el petróleo, que es el principal renglón de exportación, esmeraldas, paisajes, climas, playas y puertos sobre dos océanos, etc. (PÉREZ; BETANCUR, 2016). Así mismo, es un país con un territorio extenso, considerando que es tres veces más grande que Japón, Alemania o Italia y casi el doble que Francia (LANDINI, 2016). Adicionalmente, Colombia triplicó su producto interno bruto (PIB) en los últimos 30 años, según datos de la CEPAL (2020), lo cual denota un crecimiento exponencial. A pesar de esas ventajas, Colombia es un país subdesarrollado medianamente estable en términos económicos y con una agobiante desigualdad socioeconómica, en donde alrededor del 42.5\% de los más de 48 millones de habitantes experimentan necesidades básicas insatisfechas (DANE, 2021).

La pregunta que surge ante ese contraste, entre riqueza natural, y pobreza poblacional es: ¿Qué se hace entonces con toda la riqueza natural? ¿A qué manos llega? La respuesta a esos interrogantes no es sencilla, aunque en primer lugar puede explicarse ese fenómeno por la situación de inequidad. El coeficiente de Gini se emplea para medir la desigualdad en la distribución de los ingresos dentro de un país, con valor de 0 cuando se presenta igualdad absoluta de ingresos en toda la sociedad, ha sido tradicionalmente alto en el país y desde 2010 solo se logró que pasara de 0.563 a 0,517 en 2019 (DNP, 2019). Según este índice para el 2020, Colombia es uno de los 10 países más desiguales del mundo (BANCO MUNDIAL, 2020).

Es decir, que la riqueza se queda en una pequeña parte de la sociedad y está lejos de beneficiar a toda la población, contrario a lo que sucede en países más desarrollados como Japón con 0.321, Alemania con 0.319, Francia con 0.316 o Italia con 0.359 (BLÁZQUEZ, 2019). En consecuencia, en Colombia la diferencia de ingresos está mucho más marcada que en aquellos países, ya que la riqueza se concentra en unos pocos, mientras que la gran mayoría recibe ingresos muy bajos.

Sin embargo, el coeficiente de Gini puede ser más un síntoma del problema que una explicación o causa de que la riqueza natural no llegue a toda la población. Si bien los problemas de la sociedad colombiana se deben en buena parte al fenómeno y secuelas de violencia y narcotráfico que ha experimentado el país desde mediados del siglo XX y especialmente en los últimos decenios (RÍOS, 2017), este agobiante social no parece suficiente para explicar toda la situación. En efecto, la violencia alejó a turistas e inversionistas extranjeros. Además, dificultó las actividades de personas y empresas nacionales en varias zonas del territorio nacional, aunque no explica otro problema 
endémico que sufre el país: la corrupción, el cual contribuye en igual medida a la situación de subdesarrollo e inequidad dentro del país.

\section{ENFOQUE HISTÓRICO Y DOCTRINAL DE LA CORRUPCIÓN}

Existen ciertos teóricos clásicos y contemporáneos que han tratado de plantear hipótesis, análisis, conclusiones y acercamientos respecto al fenómeno social de la corrupción.

Según Weber (1979) su origen surge en las bases bíblicas de la creación del mundo, al relacionar el fundamento más antiguo de la corrupción con el pecado original; continuando la narración bíblica del mismo de la siguiente manera: "la corrupción del mundo por el pecado original permitía con relativa facilidad introducir en la ética, la violencia como un medio para combatir el pecado y las herejías que ponían el alma en peligro”.

Posteriormente, Klitgaard (1994) jurista y académico de Estados Unidos, quien es un analítico de las ciencias jurídicas, manifestó (acerca del soborno) que en la obra de Noonan: '[...] la corrupción es en su raíz, un problema ético y lo ha sido así durante toda la historia escrita, si bien el soborno es tan antiguo como los gobiernos propiamente dichos, esa longevidad no se debe a que el mencionado delito este aprobado en algunas culturas." (KLITGAARD, 1994, p. 25).

También se encuentra el posicionamiento de Rousseau frente al tema, quien en su obra "El contrato Social" señaló que "el hombre nace bueno y la sociedad lo corrompe" (ROUSSEAU, 1832, p. 128), frase que hace alusión a que el hombre es producto de la sociedad, puesto que cada persona al momento de nacer no posee una estructura de pensamiento moral o social y debe compenetrarse con las normas sociales que cada pueblo posee, constituyéndose en una concreta manera de pensar.

De esta forma, la persona al nacer no tiene definida su personalidad o moralidad, las adoptada en la medida en que se incorpora a la sociedad y adopta los modelos sociales impuestos por ella, abandonando el estado de pureza con que contaba al momento de su nacimiento. En contraste, señala Galán (2013) que:

De pronto la presencia misma de la corrupción pueda ser a causa de algo inherente a la esencia del ser humano y sus debilidades, aspecto que se puede denotar en frases de pensadores como Joseph Fouché, quien manifestaba que "todo hombre tiene su precio, lo que hace falta es saber cuál es" o del pensador Carlo Dossi, quien expresaba que "en todos los hombres está presente la corrupción, es solo cuestión de cantidades (GALÁN, 2013, p. 32). 
También existen académicos contemporáneos que señalan sobre la corrupción que ésta "se relaciona con malformaciones sociales" (PAREJO, 2013), idea que coincide con las apreciaciones de Rousseau.

Otra contribución sobre el tema la efectuó Calderón, al señalar que la corrupción no surge de la esfera política -la cual puede ser el entorno más común donde se manifieste- sino que surge en el núcleo familiar, cuando se desatienden las bases bíblicas tan fundamentales como la de "no robarás" (CALDERÓN, 2018, p. 41) que se encuentra presente en la gran cantidad de textos religiosos, pero que muy escasas culturas lo ponen en práctica.

Señala Calderón que cuando se nace y crece sobre los fundamentos de buenos principios, de cierta forma éstos otorgan vigor a los países en etapas de dificultades, como lo acontecido en el Japón con posterioridad al tsunami que se presentó en marzo de 2011 y que representó una posibilidad de confrontar las consecuencias aniquiladoras de este fenómeno natural y reponerse de forma acelerada. Dicha oportunidad fue posible por la aplicación de principios como la honestidad, disciplina, solidaridad y respeto, que permanecieron enraizados en la conciencia y el discernimiento de su población. La experiencia japonesa nos enseña que los momentos de crisis no necesariamente deben significar un detonante que incremente la corrupción.

De igual forma, se puede observar que la naturaleza humana de las personas, de cierta manera, representa una desventaja con relación al suceso de la corrupción, ya que toda persona puede estar siempre arriesgada a cometer un acto de corrupción de cualquier tipo; teoría que se puede afirmar teniendo en cuenta lo planteado por Han quien manifestó que "el hombre, ni siquiera por sí mismo es transparente", fundamento efectuado con relación a Sigmund Freud, quien señaló que "el yo niega precisamente lo que el inconsciente afirma y apetece sin límites, ya que en ello permanece en gran medida oculta al yo" (HAN, 2013, p. 15).

Acudiendo a los postulados del sociólogo Georg Simmel, se tiene que "estamos hechos de tal manera que no solo [...] necesitamos una determinada proporción de verdad y error como base de nuestra vida, sino también una cierta proporción de claridad y oscuridad, en la imagen de nuestros elementos de vida" (HAN, 2013, p. 36 ss). De esta forma, el propio ser del hombre y en sí el propio acontecer de la misma vida, se encontrará en constante seguimiento de una estabilidad inmejorable e ideal, ya que "la luz y las sombras se pertenecen mutuamente y con el bien, está puesto a la vez el mal" (HAN, 2013, p. 76).

En este sentido, el psicólogo Muiño citado por (Soteras, p. 2014), señaló que la corrupción se puede tomar como un germen que se expande, donde todo ser humano está expuesto a caer en ella e igualmente debe existir sensatez puesto que toda persona 
forma parte de la práctica de mínimas corruptelas -ya que conforma las culturas colectivistas- donde se comprende que lo que es bueno para cada individuo, es bueno para una colectividad.

Este análisis, según Villamil (2017), deja ver a este fenómeno como algo natural y consustancial del hombre, lo cual se ha ido direccionando al actual modelo político capitalista y se ha transformado en el motor de reproducción de la riqueza, con un alto nivel de carencia moral en su esencia. De esta forma y glosando lo expuesto por Bauman (2011, p. 10), el hombre está tan implantado en un estilo de vida que está gobernado por el consumismo y con el fin de convivir en sociedad se han debido minimizar los niveles de compromiso a nivel individual y sustituir los impulsos morales, por códigos de ética y normas de comportamiento. De la misma manera, manifiesta que "los mercados de consumo no evitan sino por el contrario, facilitan el marchitamiento, el languidecimiento y desintegración de los vínculos interhumanos" (BAUMAN, 2011, p. 107) donde estos impulsan el respeto, el compromiso y el compañerismo con el otro.

También, sobre la moral, señala Villamil (2017) que ésta se ha comercializado y, a su vez, las pretensiones de hacer el bien a los demás, lo cual "paradójicamente [...]se ha convertido en el obstáculo más colosal, cuando se trata de enfrentar las situaciones que amenazan la supervivencia de la humanidad" (BAUMAN, 2011, p. 112-113). Teniendo en cuenta estos aspectos, es de esperarse que exista la corrupción si no se confronta desde una postura ética y moral, para lo cual se requiere "la desmercantilización del impulso moral y lograr que el universo de las obligaciones morales, abarque a la humanidad entera, sin dejar de lado su dignidad y su bienestar" (VILLAMIL, 2017).

\section{LA CORRUPCIÓN EN COLOMBIA, UNA EPIDEMIA A LA QUE NO SE LE HA ENCONTRADO VACUNA}

Con el propósito de ubicar al lector frente a la realidad que se presenta en el país, en esta primera parte se incluyen datos y hechos que muestran la situación de corrupción en Colombia.

Acorde con la publicación conjunta de justicia y Fedesarrollo (NEWMAN; ÄNGEL, 2017), entre enero de 2009 y noviembre de 2016, el Sistema Penal Oral Acusatorio registró 3966 casos en los que se presentó al menos una condena por delitos relacionados con corrupción: cohecho por dar u ofrecer, omisión del agente retenedor o recaudador, peculado por apropiación y concusión. De acuerdo con ese informe:

En otras palabras, actualmente en Colombia las principales formas de manifestación de la corrupción son: i) Aceptar o exigir dinero u otra utilidad para realizar u omitir un acto propio del cargo, o para ejecutar uno contrario a 
sus deberes oficiales; ii) Retener activos que han sido confiados, para ser utilizados con fines privados; y iii) Dar un trato de favor hacia familiares o amigos, a los que se otorgan cargos o empleos públicos o incluso se facilitan permisos y licencias, por el mero hecho de serlo, sin tener en cuenta otros méritos (NEWMAN; ÄNGEL, 2017, p. 19).

El indicador cuantitativo que mayor conocimiento tiene a nivel internacional es el Índice de Percepción de la Corrupción, conocido como CPI por sus siglas en idioma inglés, el cual, desde 1995 es administrado por la organización Transparencia Internacional. En la Figura 1, se muestra la evolución del CPI para Colombia desde 2000 hasta 2019, así, la posición del país dentro de los 176 países que reporta anualmente Transparencia Internacional es la 96 dentro del ranking.

Figura 1 - Ranking mundial e Índice de Percepción de Corrupción de Colombia

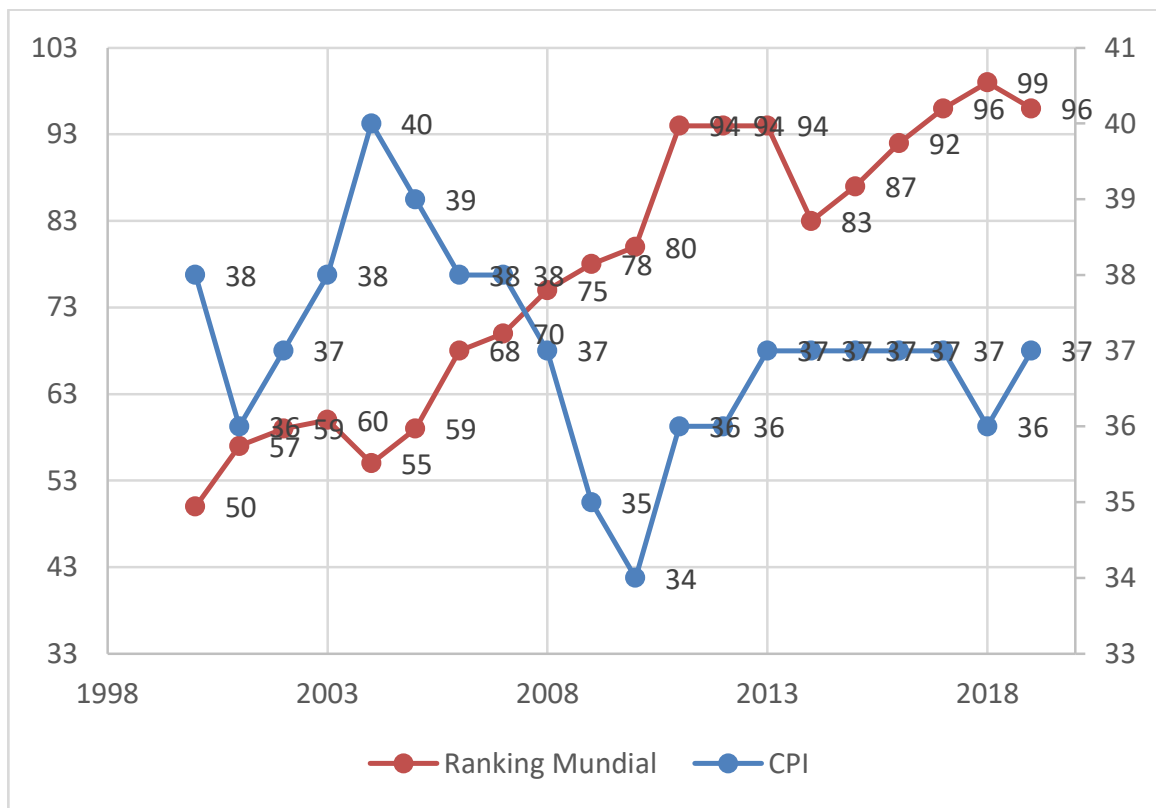

Fuente: elaboración propia, con datos de Transparencia Internacional.

De acuerdo con esas cifras, Colombia presentó un comportamiento de descenso del índice de Percepción de la Corrupción entre 2000 \& 2001 y más tarde entre 2004 \& 2010; contratio sensu, ese índice creció entre 2001 y 2004 y nuevamente ha crecido desde 2010, con lo cual se ubica en los últimos años cerca del nivel que presentaba en 2000. Esto quiere decir que no ha mejorado ni empeorado notoriamente en los últimos 19 años, a pesar de las variaciones previamente citadas. Al compararse con otros países, Colombia ha pasado de la posición 50 a comienzos del Siglo XX a la posición 96 en 2019.

Así mismo, el Banco Mundial elabora desde 1996 el Índice de Control de la Corrupción de 200 países, con base en treinta diferentes fuentes de origen ciudadano, 
empresarial, de expertos, representantes de los sectores privado y público y Organizaciones no Gubernamentales; En la Figura 2 se muestra la evolución de ese indice para Colombia.

Figura 2 - Índice de Control de la Corrupción en Colombia

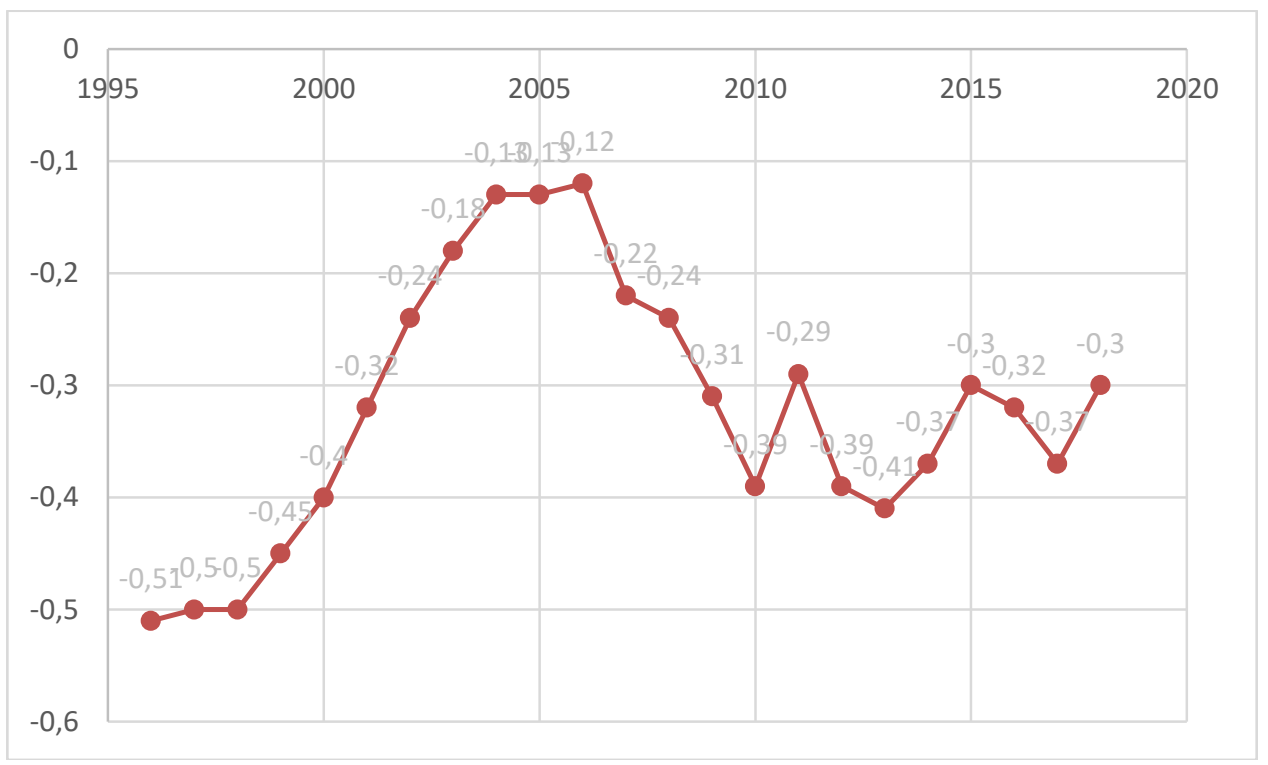

Fuente: elaboración propia con cifras del Banco Mundial.

De la figura 2 se puede concluir que el índice aumenta en la medida en que mejora el control de la corrupción, lo que quiere decir que Colombia mejoró hasta 2005; luego descendió notablemente hasta 2010, cuando empezó un comportamiento oscilatorio hasta 2018. Al comparar este índice del Banco Mundial con la Percepción de Corrupción, se observa que ambos coinciden en un deterioro de la corrupción aproximadamente desde 2003 y hasta 2010 o 2012, cuando la situación volvió a mejorar. La distinción entre los dos índices radica en que el Banco Mundial muestra la situación actual mejor que a comienzos de siglo. A diferencia de Transparencia Internacional donde la situación actual de corrupción en Colombia es similar a la que existía a comienzos del presente siglo.

De acuerdo con la Corporación Transparencia por Colombia ${ }^{1}$, "con 37 puntos sobre 100, el país se ubica en el puesto 96 entre 176 países evaluados en el índice de Percepción de Corrupción de Transparencia Internacional" (TRANSPARENCY INTERNATIONAL, 2019). El país menos corrupto es Dinamarca con 87 puntos y el más corrupto es Somalia con 9 puntos, lo que quiere decir que los 37 puntos de

${ }^{1}$ La Corporación Transparencia por Colombia -TpC-, capítulo nacional de Transparency International, nació en 1998 como respuesta de la sociedad civil colombiana a un escenario político complejo, por la incidencia de la corrupción en la institucionalidad pública y en el debilitamiento de la democracia. 
Colombia lo ubican entre los países más corruptos y no entre los menos corruptos, dado que en este índice un puntaje bajo indica mayor percepción de corrupción.

A nivel interno, en el país se conocen permanentemente noticias sobre diferentes modalidades de corrupción, especialmente en situaciones como la financiación de las campañas políticas de Senado y Cámara al igual que en las elecciones presidenciales mediante recursos aportados por contratistas del Estado (CATAÑO, 2018), evidencias de compra de votos en jornadas electorales (ANTOLÍNEZ, 2018), adjudicación de contratos mediante pliegos de condiciones elaborados a la medida de determinados proponentes a los que se busca favorecer (BARBOSA; SOTO; ROJAS, 2019), designación de funcionarios públicos sin el cumplimiento de requisitos mínimos (POTES; TRIANA, 2016), adulteración de certificaciones académicas para acceder a determinados cargos (SÁNCHEZ, 2017), tráfico de influencias para la manipulación de fallos judiciales (CALDERÓN, 2018), designación de familiares en cargos de elección popular cuando los titulares originales son investigados (SANDOVAL, 2016), además de abusos de poder en beneficio personal o de terceros (nepotismo), entre otras muchas prácticas.

De acuerdo con esto, se tiene que la situación de corrupción es tan crítica en el país que ha logrado debilitar, o al menos cuestionar, la capacidad del aparato judicial para castigar a los responsables. El entorno se muestra aún más inoperante si se tiene en cuenta que existen cuestionamientos sobre la capacidad de acción del Consejo Nacional Electoral para juzgar los fenómenos de corrupción asociados a las diferentes campañas de elección popular, debido a que este organismo tiene origen en el mismo Congreso que designa a sus integrantes, por lo que su vocación es más política que jurídica (ABRIL, 2019), como se refleja en sus fallos.

Así mismo, en cuanto a los hechos de corrupción que se presentan en el Congreso, la Comisión de Acusaciones está tan desprestigiada que es conocida popularmente como la Comisión de Absoluciones (JIMÉNEZ, 2018), pues inclusive se abstuvo de tomar medidas drásticas contra un presidente de la República que reconoció haber sido elegido en una campaña financiada con recursos del Narcotráfico (ESPINOSA, 2017).

Adicionalmente, el diseño mismo del sistema anticorrupción presenta debilidades, si se tiene en cuenta que:

En 2011 se sustituyó el Programa Presidencial de Lucha contra la Corrupción por la Secretaría de Transparencia, con la misión de asesorar y apoyar directamente al presidente de la República en el diseño de una Política Integral de Transparencia y Lucha contra la Corrupción y coordinar su implementación. Mediante el Decreto 1784 del 04 de octubre de 2019, se reestructuró el Departamento Administrativo de la Presidencia de la 
República y se consignaron diferentes funciones para la Secretaría de Transparencia (SECRETARÍA DE TRANSPARENCIA, 2020, en línea).

Es decir, el diseño de la política de transparencia y lucha contra la corrupción está en cabeza de una persona designada de manera discrecional por el ejecutivo, con todas las consecuencias que eso puede tener en cuanto a la forma en que se realizan los controles y se adoptan las disposiciones tendientes a prevenir, evitar, controlar, perseguir y castigar a los responsables de corrupción en el Estado.

Si bien existen otros órganos de control como la Fiscalía General de la Nación, la Corte Suprema de Justicia, la Procuraduría General de la Nación, y la Contraloría General de la República, ninguno de ellos tiene como función esencial la gestión para la transparencia. Lo que evidencia la dependencia de esa oficina frente a una de las ramas del poder; en este caso el ejecutivo, es el problema de la transparencia y la lucha contra la corrupción existente en el organigrama de la institución, limitando las expectativas de lograr superar la corrupción en el país.

En otras palabras, detrás de los inconvenientes jurídicos que dan origen a la persistencia de la corrupción en diferentes hechos de la vida nacional, parece existir un problema filosófico o ético. Puede ser filosófico en la medida en que las fallas de diseño del sistema de lucha contra la corrupción, o en términos positivos, las fallas de diseño del sistema para la promoción de transparencia se deban al desconocimiento de que las causas que generan corrupción requieren combatirse desde afuera del mismo sistema corrupto.

Por tanto, resulta contradictorio esperar que el mismo sistema corrupto tenga interés en que esa lucha efectivamente se gane. Esa contradicción se ha hecho evidente, por ejemplo, en el trámite fallido de leyes que han buscado eliminar privilegios para los congresistas (RAMÍREZ; ZAPATA, 2019) y en la fracasada consulta anticorrupcion del año 2018. Sin embargo, las fallas de diseño del sistema de lucha contra la corrupción también podrían tener una explicación de carácter ético, en la medida en que ese diseño hubiera sido hecho con el propósito de que resulte inoperante.

Independientemente de cuál sea la causa de su inoperancia, lo cierto es que el diseño de ese sistema debe mejorarse, teniendo presente que el ser humano puede incurrir en actos de corrupción, faltas éticas y las deficiencias educativas o formativas que pudieran explicar tales conductas, siendo necesario un sistema jurídico integral que deba adaptarse o concebirse de acuerdo con las razones filosóficas que explican el comportamiento humano frente a las situaciones que requieran decidir si actuar, o no, de forma corrupta.

Precisamente por las cargas ético, filosófico y morales, al momento de asumir una decisión, cabe señalar que en el mundo existen diferentes esquemas judiciales para 
enfrentar la corrupción, que van desde los más tolerantes, hasta los más extremos, en donde la corrupción se castiga con pena de muerte (CADILLO; JARA, 2018). Tal vez ninguno de los dos resuelva realmente el problema, motivo que genera -antes de cuestionar el sistema jurídico colombiano- inviar a un ejercicio reflexivo donde se busque comprender, de la mano de los expertos que han analizado el asunto, lo que sucede en la mente humana cuando se enfrenta a debates que involucran asuntos éticos. Esa comprensión se requiere para pasar después a estudiar el diseño jurídico de un sistema de lucha contra la corrupción en cualquier país del mundo.

Por otro lado, existen síntomas que no necesariamente son cuantitativos y que permiten ampliar la caracterización de la situación; si bien la corrupción ya es una lamentable tradición en Colombia, especialmente en la contratación pública, preocupa que en los años recientes se han presentado hechos de corrupción en áreas de la gestión pública en los que se esperaría que hubiera comportamientos escrupulosos.

Por ejemplo, se tiene la existencia de sectores marcados por los escándalos de corrupción como la construcción de obras civiles, la salud (MENDIETA; JARAMILLO, 2020, p. 97), la educación, programas específicos como el de Alimentación Escolar PAE en diferentes regiones del país (PEDREROS; DÍAZ, 2017), y aquellos destinados a la atención de salud en temas puntuales como el denominado Cartel de la Hemofilia (GARAY; SALCEDO; ÁLVAREZ, 2010). La figura 3, permite observar cuales son los sectores más afectados por la corrupción en Colombia.

Figura 3 - Sectores más afectados por hechos de corrupción (2016-2018)

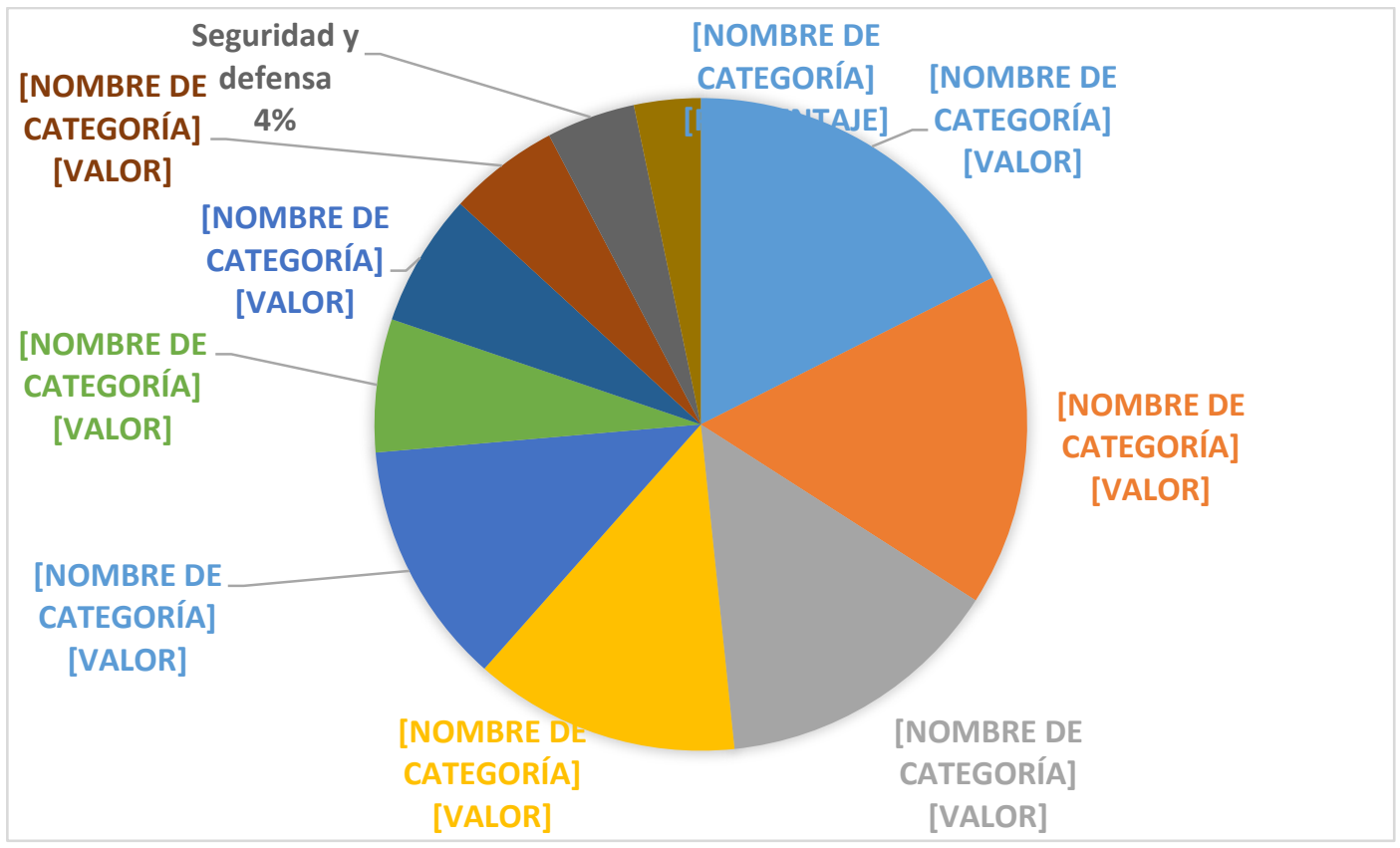

Fuente: Figura elaborada con datos derivados del tercer informe del Monitor Ciudadano de la Corrupción a partir de registros de prensa nacional y regional (2019). 
Como situaciones recientes y actuales, se han presentado otros hechos similares o más delicados, como las denuncias por presuntos actos de corrupción en los procesos de contratación pública que se han adelantado en diferentes regiones del país para dar respuesta a la pandemia del COVID-19 (SANABRIA P., 2020). Si bien se trata de hechos recientes que apenas se encuentran en fase de investigación preliminar por parte de las autoridades correspondientes, la existencia de la sospecha respecto a prácticas orientadas a evadir las medidas preventivas dentro de la contratación estatal y que la Procuraduría General de la Nación haya adoptado medidas para su control (2020), permite concluir que frente a la mayor crisis de salubridad que ha enfrentado el país, los recursos públicos destinados a enfrentarla se encuentran en peligro. Las crisis no detienen a los corruptos, todo lo contrario, los estimula.

Así mismo esa situación evidencia que la solución radical de la problemática de corrupción, probablemente, no se encontrará en la persecución de prácticas corruptas o en la creación de medidas preventivas para detectarla y eliminarla. Al fin y al cabo, la creatividad para encontrar nuevas alternativas que faciliten propósitos corruptos pueden ir siempre uno o varios pasos delante de los organismos delegados para esa persecución.

Tal vez, la verdadera solución radical contra la corrupción está en identificar las razones éticas, de educación y de formación de valores que deberían blindar a la sociedad de ese tipo de prácticas. Sin embargo, para validar esa hipótesis se debería estudiar la situación de corrupción en países con sistemas de formación con más énfasis en esos aspectos, así como las medidas de carácter investigativo y penal que existen en los países con mejores resultados en esa batalla.

\section{IMPACTO DE LA CORRUPCIÓN EN TIEMPOS DE COVID-19 EN COLOMBIA}

El pasado 12 de marzo de 2020, el gobierno colombiano declaró el Estado de Emergencia Sanitaria, esta medida se asumiría a raíz de la declaratoria de pandemia de la Organización Mundial de la Salud y siguiendo los parámetros establecidos. Lo anterior como sustento para la implementación de un marco normativo que permita adoptar medidas rápidas y necesarias, con el fin de agilizar la labor de las autoridades y facilitar el uso de los recursos públicos. La declaratoria de la emergencia sanitaria fue viable jurídicamente gracias a competencias dadas al gobierno nacional y a los gobiernos locales por el Código Nacional de Policía y se limitaron muchos derechos constitucionales como las libertades de movilización, reunión, culto, protesta social, actividad comercial, a pesar de que en el caso colombiano la limitación de estos derechos requiere norma con fuerza de ley. 
También se declararon dos estados de emergencia social, que en Colombia representa uno de tres estados de excepción establecidos en la Constitución de 1991, siendo las medidas tomadas allí delimitadas especialmente en materia económica. Durante la crisis generada por el virus del COVID-19, el país también vivió una crisis institucional y humanitaria generada por el uso y abuso de las normas expedidas para enfrentar la pandemia (MENDIETA; TOBÓN, 2020, p. 243).

Con tristeza, la urgencia de la crisis sanitaria ha traído consigo la omisión de principios como la transparencia en el uso de los recursos públicos, al punto que se ha convertido las ayudas en un festín para muy pocos; pero solo los que se encuentran en una relación muy directa con el poder ejecutivo de turno a nivel nacional, departamental y municipal, es una oportunidad para aumentar sus ingresos en detrimento de los del común.

Lo anterior, aunado a las múltiples instituciones y prestadores de los servicios de salud, quienes desde hace años tienen debilidades y vacíos, generando que los riesgos de corrupción sean más altos. A mayo de 2020, cuando apenas habían transcurrido los primeros dos meses de la emergencia sanitaria generada por el COVID-19, la Procuraduría reportó la priorización de 2.562 actuaciones "de las cuales 1.563 corresponden a acciones preventivas dirigidas a evitar la vulneración de los derechos de los ciudadanos, hechos de corrupción o mal uso de los recursos públicos, en especial los destinados para ayudas humanitarias" (PROCURADURÍA GENERAL DE LA NACIÓN, 2020, p. 1).

De acuerdo con el boletín de la Superintendencia de Sociedades correspondiente al mes de agosto:

Factores tales como, las condiciones propias de la crisis, la contratación pública en estados de emergencia, la comercialización de insumos médicos sin los estándares requeridos, el aumento sustancial de las operaciones financieras remotas o no presenciales, entre otros, hacen que el entorno global se encuentre mucho más propenso a los actos de corrupción (SUPERSOCIEDADES, 2020, en línea).

Por tanto, no es de extrañar que "transparencia para la emergencia" siendo una iniciativa de las tres entidades de control (la Fiscalía General de la Nación, la Contraloría General de la República y la Procuraduría General de la Nación) unidas para presentar, vigilar y controlar de manera armónica y coordinada en la lucha contra la corrupción, muestra que durante la primera parte de la crisis generada por el virus del COVID-19, entre el 17 de marzo y el 17 de julio, se celebraron en Colombia 19.882 contratos de entidades del Estado para atender la emergencia, de éstos el 85\% fue por contratación directa, es decir, sin cumplir muchos de los requisitos que han sido 
establecidos en el país para evitar actos de corrupción, 3\% contratación mediante régimen especial y el 2\% restante, bajo otras modalidades (2020).

De lo anterior se evidencia que la contratación directa es problemática porque la falta de varios oferentes imposibilita la obtención de mejores precios y calidad de los productos o servicios a contratar. La incertidumbre de la población en materia económica ha generado que el nivel de interés por ejercer veedurías y control social sea irrisorio, además que el miedo al contagio hace que menos personas estén dispuestas a hacerle control social al gasto público.

Situación que ha sido aprovechada por los ordenadores del gasto, quienes han presentado irregularidades como la no publicación de contratos en la plataforma gubernamental Colombia Compra Eficiente (SECOP), sobrecostos en las compras de alimentos para los más vulnerables y uso de recursos en contratos de publicidad y comunicaciones sobre la COVID-19; irregularidades en la compra de utensilios para el sector de la salud y sobrecostos en elementos como camas, camillas, ventiladores, monitores; alzas exageradas en los precios de alimentos, medicamentos, dispositivos médicos y elementos de aseo y limpieza.

Lo anterior fue enunciado por la Fundación Paz y Reconciliación (2020) en su investigación en torno al manejo de los recursos públicos de los entes territoriales para la atención de la pandemia donde se encontró 313 contratos por cientos de miles de millones de pesos de 118 entes territoriales en 29 de los 32 departamentos de Colombia y su Distrito Capital, en los cuales habría presuntas irregularidades.

En consecuencia, el clima de desconfianza en las instituciones debido a la ineficacia en el control de la corrupción (Vélez, 2020) ha llevado a que se cuestionen diferentes medidas que el Estado ha tomado durante la emergencia generada por el COVID-19. Sirve de ejemplo la situación que se presentó en el mes de septiembre cuando se anunció por parte del Gobierno Nacional un préstamo por $\$ 370$ millones de dólares a la aerolínea Avianca como medida para su rescate económico ante las consecuencias que esa empresa ha tenido por el cierre de los aeropuertos nacionales e internacionales.

A pesar las explicaciones brindadas sobre la importancia estratégica de que el país cuente con una empresa aérea capaz de garantizar la prestación del servicio de transporte aéreo de carga y de pasajeros, la presión de la opinión pública y la desconfianza llevaron a que la Contraloría General de la Nación abriera una investigación administrativa que busca evaluar los argumentos técnicos que sustentaron esa decisión (CONTRALORÍA GENERAL DE LA NACIÓN, 2020) y a que el Tribunal Superior de Cundinamarca suspendiera el desembolso del prestamo como medida cautelar. Es importante resaltar que hoy Avianca no es una empresa colombiana y al mismo tiempo que el Gobierno 
Nacional ofreció este préstamo a la empresa aérea, el país se encontraba buscando recursos en la banca internacional.

Situaciones como las mencionadas con anterioridad y otras relacionadas con contratos, como el que suscribió la Presidencia de la República con la firma Du Brands para evaluar la percepción del Presidente de la República en redes sociales (PROCURADURÍA GENERAL DE LA NACIÓN, 2020) evidencia que, además del daño ocasionado de forma directa en las finanzas del Estado y en la salud en general de la economía nacional, la corrupción se caracteriza por generar un clima de desconfianza que dificulta la celebración tranquila de los contratos que se necesitan para que las instituciones públicas cumplan con la misión que les señalan la Constitución y la ley.

Así, en este momento se hace justo, racional, y necesario el buen uso y aprovechamiento de los recursos públicos, pues la buena o mala utilización del dinero se ve reflejado en la vida de una persona. De ahí que se considere a los recursos públicos como sagrados, sobre todo en esta época, cuando está en juego la posibilidad de garantizar la oportuna atención en salud, insumos e infraestructura para los más vulnerables y -como si fuera poco- de manera paralela mantener activo el tejido empresarial que es el que se encarga de dar, mantener y conservar el empleo y las empresas para mitigar o conjurar el hambre y las necesidades.

Según datos del Instituto Internacional de Estudios para la Paz de Estocolmo (SIPRI, por sus siglas en ingles), Colombia es el país que más invierte en gasto militar en Suramérica en relación con su PIB y para el año 2.019 ascendió al 3.2\%, lo que es una suma considerable si se tiene en cuenta que para el mismo periodo Brasil gastó el 1.5\%, México el 0,5\% o Chile el 1.8\% de sus respectivos PIB (SIPRI, 2020, p. 2).

Según Fernando Carrillo en un discurso dado ante la Asamblea de las Naciones Unidas, la corrupción le cuesta a Colombia el 5\% de su PIB, el 15\% del presupuesto nacional y afecta por sobornos y coimas el 18\% de la contratación pública de la región e incluso califica el problema como "La historia en los últimos 15 años en la lucha contra la corrupción es una historia de luces y sombras, donde pasamos de un mal endémico y hoy podemos hablar fácilmente de una epidemia, casi de una pandemia que exige respuestas internacionales" (CARRILLO, 2018, en línea).

Es verdad que a nivel global vivimos la peor pandemia de los últimos tiempos, pero en el caso colombiano hay una epidemia que desangra los recursos públicos desde hace mucho tiempo: la corrupción. Como hace poco lo advirtió el fotógrafo colombiano Jesús A. Colorado: "El silencio de los fusiles hizo que escucháramos el ruido de la corrupción, por ello vuelven a sonar los fusiles para silenciar la corrupción”. Es triste, pero difícilmente otra frase puede resumir mejor la situación actual de Colombia. 


\section{CONSIDERACIONES FINALES}

En suma, de acuerdo con las cifras expuestas en la primera parte de este artículo, tanto el sistema judicial como el sistema disciplinario colombianos tienen evidencias concretas de los actos de corrupción que se presentan en las entidades del Estado; sin embargo, se trata de evidencias que solamente conducen a sanciones en un porcentaje cercano al 22\% de las denuncias. Los delitos que con mayor frecuencia son denunciados corresponden a apropiación de bienes públicos a cambio de omitir actos que son responsabilidad de los servidores públicos y que implican retener activos del Estado para utilizarlos en beneficio de particulares y favorecer a determinadas personas frente procesos de contratación estatal.

También se pudo determinar que la percepción de corrupción en el país ha tenido un comportamiento cíclico; esos ciclos tienen una frecuencia que se aproxima a los períodos presidenciales, como lo muestra la Figura 1. En la que se observa que los períodos de incremento o descenso de la percepción de corrupción cambian cada cuatro u ocho años aproximadamente.

Adicionalmente, se refleja que cada vez la corrupción se manifiesta en procesos de contratación estatal que involucran, ya no solamente obras de infraestructura, sino programas de asistencia social como el Programa de Alimentación Escolar o las estrategias para la atención a la pandemia del COVID-19. En el país el tipo de actos corruptos muestran que los escrúpulos son cada vez menores al momento de apropiarse indebidamente de recursos destinados a programas de interés social.

Finalmente, la investigación realizada permite concluir que en Colombia la corrupción se ha convertido en una epidemia que desangra los recursos públicos, siendo incluso más onerosa que la misma guerra. Además, que la mayor emergencia sanitaria de la historia ocasionada por el virus del COVID-19, ha requerido la intervención inmediata de las entidades del Estado, permitiendo la contratación directa, dejando en peligro a billones de pesos invertidos para atender esta situación, lo cual demuestra que un país como Colombia las crisis no detienen a los corruptos, por el contrario, los estimula.

\section{REFERENCIAS}

ABRIL, Stefanny Johana. Autonomía de los órganos electorales: i cuál es la dimensión de la autonomía del Consejo Nacional Electoral?. Bogotá: Universidad Externado de Colombia, 2019.

ANTOLÍNEZ, William Alexander. Mirada crítica a la democracia representativa colombiana: Un análisis económico de la compra y venta de votos en el país. Ainkaa. 
Revista de Estudiantes de Ciencia Política, v. 2, n. 4. p. 69-86, 2018.

BANCO MUNDIAL. Índice de Gini de Colombia. Disponible en: https://datos.bancomundial.org/indicador/SI.POV.GINI?view=map\&locations=CO. Consultado en: 30 agosto 2020.

BARBOSA, José Miguel; SOTO, Miguel Darío; ROJAS, Ronny Johan. Análisis de pliegos tipo para la transparencia en la adjudicación de proyectos de infraestructura de transporte en Colombia, en comparación con países como Argentina y República Dominicana. Bogotá: Universidad Piloto de Colombia, 2019.

BAUMAN, Zygmunt. Daños colaterales: desigualdades sociales en la era global. Madrid: Fondo de cultura económica, 2011.

BLÁZQUEZ, Loreto Machés. Análisis geopolítico: la talla de los actores internacionales. Bie3: Boletín IEEE, v. 12, p. 486-511, 2019.

CADILlO, Gaby Carin; JARA, Pedro Pablo. La influencia de la benignidad de las penas en los delitos de corrupción de funcionarios. Huaraz, Perú: Universidad César Vallejo, 2018.

CALDERÓN, Diego Javier. Redes de corrupción política: una revisión para el caso colombiano. Análisis político, v. 31, n. 92, p. 180-201, 2018.

CATAÑO, Ana Marcela. Entre el clientelismo político y la contratación pública: una aproximación a las prácticas clientelares en el municipio de Sahagún Córdoba durante el período 2008-2015. Medellín: Universidad de Antioquia, 2018.

CARRILLO, Fernando. Discurso ante la Asamblea Nacional de las Naciones Unidas. 2018. Disponible en: https://www.procuraduria.gov.co/portal/Lacorrupcion__es_casi_una_pandemia_que_exige_respuestas_internacionales__Procurad or.news.

CEPAL. Estadísticas e indicadores económicos, cuentas nacionales anuales en dólares. Colombia. Disponible en: https://estadisticas.cepal.org/cepalstat/tabulador/Consulta IntegradaProc_HTML.asp Consultado en: 30 agosto 2020.

CORPORACIÓN TRANSPARENCIA POR COLOMBIA. Así se mueve la corrupción: radiografía de los hechos de corrupción en Colombia: 2016-2018. Disponible en: https://transparenciacolombia.org.co/Documentos/2019/InformeMonitor-Ciudadano-Corrupcion-18.pdf, Bogotá, 2019.

CONTRALORÍA GENERAL DE LA NACIÓN. El colombiano: Contaloria le pone la lupa al préstamo de Avianca. Disponible en: https://www.contraloria.gov.co/contraloria/sala-de-prensa/registro-de-prensa//asset_publisher/JLthS7umE1tZ/content/elcolombiano-com-contraloria-le-pone-la-lupaal-prestamo-que-el-gobierno-le-dara-a-avianca?inheritRedirect=false, 2020. Consultado en: 30 agosto 2020.

DANE. Necesidades básicas insatisfechas (NBI). Disponible en: 
https://www.dane.gov.co/index.php/estadisticas-por-tema/pobreza-y-condiciones-devida/necesidades-basicas-insatisfechas-nbi, 2020. Consultado en: 20 agosto 2020.

DNP. Promoción de la equidad y reducción de la pobreza. 2019. Disponible en: dnp.gov.co: https://www.dnp.gov.co/programas/desarrollo-social/pol\%C3\%ADticassociales-transversales/Paginas/promoci\%C3\%B3n-de-la-equidad-y-reducci\%C3\%B3n-dela-pobreza.aspx, 2019. Consultado en: 25 agosto 2020.

FUNDACIÓN PAZ Y RECONCILIACIÓN. El cuestionado manejo de los recursos públicos en medio de la pandemia. Disponible en: https://www.justiciaypazcolombia.com/el-cuestionado-manejo-de-los-recursos-publicosen-medio-de-la-pandemia/. Consultado en: 7 agosto 2020.

ESPINOSA, Julian. Actuación del congreso de la república de Colombia en el periodo presidencial 1994-1998, frente a la infiltración de dineros del narcotráfico en las campañas políticas. Bogotá: Universidad Gran Colombia, 2017.

GALÁN, A. Buena administración e instrumentos jurídicos de lucha contra la corrupción, la experiencia española. En: MORELLI RICO, Sandra et al. República, La corrupción, flagelo mundial. Colombia: Bogotá, 2013. p. 34-45.

HAN, Byung Chul. La sociedad de la transparencia. Trad. R. Gabás. Barcelona: Herder, 2013.

IKENBERRY, G John. La crisis del orden liberal mundial. Anuario Internacional CIDOB, p. 29-36, 2019.

JIMÉNEZ, Diego Mauricio. Juicio a la legitimidad del legislador en Colombia. Verba luris, v. 40, p. 25-47, 2018.

KLITGAARD, Robert. Controlando la corrupción. Una indagación práctica para el problema social de fin de siglo. Buenos Aires: Editorial Sudamericana S.A, 1994.

LANDINI, Fernando. Concepción de extensión rural en 10 países latinoamericanos. Andamios, v. 13, n. 30, p. 211-236, 2016.

LARA, Juan Sebastian; TOSI, Andre; ALTIMIRAS, Aleix. Platinum and Gold Mining in Chocó: Poverty, Natural Wealth and Informality. Revista de Economía Institucional, p. 22-42, 2020.

NEWMAN, Vivian; ÄNGEL, Maria P. Sobre la corrupción en colombia: marco conceptual, diagnóstico y propuestas de política. Bogotá: Dejusticia, Fedesarrollo, 2017.

MENDIETA, David; JARAMILlO, Carmen. ¿Qué ha pasado con los principios de Universalidad, Solidaridad y Eficiencia del Sistema General de Seguridad Social en Salud de Colombia? Revista Brasileira de Políticas Públicas, Brasília, v. 10, n. 1, p. 86102, 2020.

MENDIETA, David; TOBÓN Mary Luz. La pequeña dictadura del COVID-19 en Colombia: uso y abuso de normas ordinarias y excepcionales para enfrentar la pandemia. Revista Opinión Jurídica, v. 19, n. 40, 2020. 
PAREJO, A. Corrupción y lucra contra su manifestación. El caso de España. En: MORELLI RICO, Sandra et al. Repúbica, La corrupción, flagelo mundial. Ponencias Tomo II. Colombia: Bogotá, 2013. p. 123-153.

PÉREZ, Margarita; BETANCUR, Angie. Impactos ocasionados por el desarrollo de la actividad minera al entorno natural y situación actual de Colombia. Sociedad y Ambiente, v. 10, p. 95-112, 2016.

POTES, Luis Carlos; TRIANA, Mariana. Inhabilidades e incompatibilidades de los funcionarios públicos para contratar con el Estado. Bogotá: Universidad La Gran Colombia, 2016.

PROCURADURÍA GENERAL DE LA NACIÓN. Procuraduría adelanta 512 procesos disciplinarios por presuntas irregularidades en 26 gobernaciones y 272 alcaldías en la emergencia sanitaria por COVID-19. Disponible en : https://www.procuraduria.gov.co/portal/-Procuraduria-adelanta-512-procesos disciplinarios-por-presuntas-irregularidades-en-26-gobernaciones-y-272-alcaldias-en-laemergencia-sanitaria-por-COVID-19.news, 21 de mayo de 2020. Consultado en: 30 julio 2020.

RAMÍREZ, Juan Felipe; ZAPATA, Santiago. Marco comparativo de la economía y la corrupción desde la perspectiva pública y privada con datos de la Organización para la Cooperación y el Desarrollo Económico y la Organización de Estados Americanos en los períodos 2004 - 2017. Bogotá: Universidad del Bosque, 2019.

RÍOS, Jeronimo. El Acuerdo de paz entre el Gobierno colombiano y las FARC: o cuando una paz imperfecta es mejor que una guerra perfecta. Araucaria. Revista Iberoamericana de Filosofía, Política y Humanidades, v. 19, n. 38, p. 593-618, 2017.

ROUSSEAU, Juan Jambo. El contrato social, ó Principios del Derecho político. Londres: Universidad Complutense, 1832.

SÁNCHEZ, Hector Mauricio. Panorama ético del contador publico en Colombia, de acuerdo con los datos estadísticos de la junta central de contadores en los últimos 5 años. Bogotá: Universidad Militar Nueva Granada, 2017.

SANDOVAL, Camilo Andres. Transferencia del voto en las regiones: redes electorales nacionales y territoriales del Partido de la U en Córdoba y Sucre. Bogotá: Universidad del Rosario, 2016.

SECRETARÍA DE TRANSPARENCIA. Funciones de la Secretaría de Transparencia. Disponible en: http://www.secretariatransparencia.gov.co/secretaria/funciones. Consultado en: 1 agosto 2020.

SIPRI. Trends in world military expenditure, 2019. Disponible en: https://www.sipri.org/sites/default/files/2020-04/fs_2020_04_milex_0_0.pdf, 2020. Consultado en: 1 agosto 2020.

SOTERAS, Ana. (s.f.). Fatalismo o indignación: ¿Cómo afecta la corrupción a la salud 
mental? Disponible en: http://www.efesalud.com/noticias/la-sociedad-frente-a-lacorrupcion-del-fatalismo-a-la-indignacion/, 2014. Consultado en: 12 agosto 2020.

SUPERSOCIEDADES. Riesgo de soborno trasnacional y otras prácticas corruptas en tiempos de COVID-19. Disponible en: https://www.supersociedades.gov.co/Noticias/Publicaciones/Revistas/2020/Boletininformativo-Covid-Soborno.pdf, 2020. Consultado en: 12 agosto 2020.

TRANSPARENCY INTERNATIONAL. Índice de percepción de la corrupción 2019. Disponible en: https://transparenciacolombia.org.co/wp-content/uploads/cpi2019. report-es-web-1.pdf, 2019. Consultado en: 1 agosto 2020.

TRANSPARENCIA POR COLOMBIA. Informe sobre corrupción en contratos durante la pandemia. Disponible en: https://www.colombia.com/actualidad/economia/transparencia-por-colombiacorrupcion-contratos-pandemia-coronavirus-covid19-278249, 2020. Consultado en: 30 agosto 2020.

VÉLEZ, Carlos Alberto. La corrupción en Colombia, aproximación al contexto sociopolítico antes y después de la Constitución de 1991. Bogotá: Universidad Nacional de Colombia, 2020.

VILLAMIL, Jesus Emerio. La corrupción en Colombia, aproximaciones conceptuales y metodológicas para abordarla. Medellín: Universidad Nacional de Colombia, 2017.

WEBER, Max. El político y el científico. Madrid: Alianza editorial,1979.

\section{NOTA}

Los autores Gressy Kareny Rojas Cardona y David Mendieta en el desarrollo del artículo titulado "CORRUPCIÓN: LA MAYOR EPIDEMIA QUE SUFRE COLOMBIA" ejercieron funciones conjuntas y complementarias para la composición del mismo. La investigación y redacción bibliográfica se llevó a cabo principalmente por Gressy quien es estudiante del Doctorado en Derecho de la Universidad de Medellin y la organización metodológica, revisión y orientación científica por David Mendieta quien ostenta la calidad de director de tesis. De esta manera, los autores entienden que los aportes en la construcción del artículo se dieron de una manera armónica y bajo la figura de la cooperación y apoyo mutuo.

\section{Como citar este documento:}

CARDONA, Gressy Kareny Rojas; MENDIETA, David. Corrupción: la mayor epidemia que sufre Colombia. Revista Opinião Jurídica, Fortaleza, v. 19, n. 32, p. 296-315, set./dez. 2021. 